\title{
Influence of Surface Texture of Implants on Microorganism - A Review
}

\author{
Gayathri Karan Rajpurohit ${ }^{1}$, Arvina Rajasekar ${ }^{2}$ \\ 1, 2 Department of Periodontics, Saveetha Dental College, Saveetha Institute of \\ Medical and Technical Sciences, Chennai, Tamil Nadu, India.
}

\section{ABSTRACT}

\section{BACKGROUND}

The development of endosseous osseointegrated dental implants has been very rapid over the past 20 years. The present literature review focuses on evaluating the various modifications done on the surface of dental implant and its influence on microorganisms. We wanted to review the evidence on the surface texture of implants and its influence on microorganisms.

\section{METHODS}

A Medline research was done, and all the information was gathered from various research articles. The keywords on the search pad were "implant", "surface texture", "surface modifications ", "biofilm", "bacterial attachment", "adhesion", "microbes", "antibacterial", "acid etching", "subtractive" and "additive" changes. The research publications were searched on Google Scholar and PubMed. Screening of studies which were eligible for the review, quality assessment, inclusion criteria, exclusion criteria and data extraction for all the endosseous implants with various surface modifications were checked. Verification of the information was conducted by two reviewers independently to eliminate any bias. The review article included systemic analysis, retrospective study and randomised trials. The results were all initially tabulated comparing the surface modifications with their effect on implant including bacterial resistance, osteogenic, osteoconductive etc. Based on the evidence the results were formulated, and the conclusion was made.

\section{RESULTS}

It's clear from the evidence that there was no constancy in the results obtained. Each study believes in different techniques and different ideologies of the researcher to improve the microbial resistance either by coating or by surface modification. Due to the varying pattern of results, it is difficult to identify a definite reason for the microbial load over the implant.

\section{CONCLUSIONS}

There was no constancy in the results obtained. Overall, there are many technical solutions to avoid implant failure due to the bacterial load. These technical solutions exhibit a great potential when tried on preclinical models but there is a lack of clinical trial which hinders the achievement of any proper conclusion to build a standard protocol for the manufacturing of dental implants with structural modification. As implants are considered to be the most effective way to replace a missing tooth, standard technique with better surface texture is required to have good strength and better microbial resistance.

\section{KEY WORDS}

Surface Texture, Implant, Biofilm, Microbial Load, Modifications, Antimicrobial, Osseoconductive, Osseointegration
Corresponding Author: Dr. Arvina Rajasekar, Senior Lecturer, Department of Periodontics, Saveetha Dental College, Saveetha Institute of Medical and Technical Sciences,

Chennai, Tamil Nadu, India.

E-mail: arvinar.sdc@saveetha.com

DOI: $10.14260 / j e m d s / 2021 / 430$

How to Cite This Article:

Rajpurohit GK, Rajasekar A. Influence of surface texture of implants on microorganism-a review. J Evolution Med Dent Sci 2021;10(28):2104-2107, DOI: $10.14260 /$ jemds/2021/430

Submission 08-09-2020,

Peer Review 12-05-2021,

Acceptance 19-05-2021,

Published 12-07-2021.

Copyright (C) 2021 Gayathri Karan Rajpurohit et al. This is an open access article distributed under Creative Commons Attribution License [Attribution 4.0 International (CC BY 4.0)] 


\section{BACKGROUND}

The development of end osseous osseointegrated dental implants has been very rapid over the past 20 years. There are now many dental implant systems available that provide the clinician with design features that facilitate easy treatment, aesthetics, high degree of predictability to attain osseointegration with low complication rate, easy maintenance, easy surgical and prosthetic protocols. The development of a biocompatible material with varying length and diameter was indeed the primary success obtained in the field of implantology ${ }^{1}$. Surface modification investigations that favour osteoconductivity and osseointegration are area of active research for the development of implant. While osteoconductivity deals the new bone formation due to cell activity osseointergration deals with the bone and loaded titanium implant binding. 2,3

Evidences on implant with smoother electro-polished surface claimed that the implant was surrounded by lesser bone in comparison to the one with machined implants and roughened surface. ${ }^{4}$ But on the other hand studies do also support the fact that with increase in surface roughness and surface free energy there was an increased biofilm formation on the implant surface which affects the normal cell proliferation on implant which in turn effects the osseointegration process of bone and implant binding. ${ }^{5}$

The present review literature focuses on evaluating and tabulating the results of various modifications done on the surface texture of dental implant and it also compares the outcome of each of this modification with its influence on the microbial colonisation.

\section{METHODS}

A MedLine research was done, and all the information was gathered from various research articles through the online source obtaining the conclusion. The keywords on the search pad included were "implant", "surface texture", "surface modifications ", "biofilm", "bacterial attachment", "adhesion", "microbes", "antibacterial", "acid etching", "subtractive" and "additive" changes. The research publications were searched on Google Scholar and PubMed. Screening of studies which were eligible for the review, quality assessment, inclusion criteria, exclusion criteria and data extraction for all the endosseous implant with various surface modifications were checked. Verification of the information was conducted by two reviewers independently to eliminate any bias. The review article included systemic analysis, retrospective study and randomised trials.

The results were all initially tabulated comparing the surface modifications with their effect on implant including bacterial resistance, osteogenic, osteoconductive etc. Based on the evidence the results were formulated and the conclusion was made.

\section{RESULTS}

While studies suggested that acid etching of implants produced high roughness surface modification which was the most effective method of all the surface modification ${ }^{6}$ but on the other hand it also provides abundant binding sites for the bacterial attachments, thus, increased risk of infection and implant failure. ${ }^{7,8,9}$ Strong evidences were provided by reports stating that there is increased bacterial adhesion with increased surface roughness and wettability. ${ }^{10}$ It accounts for the initial attachment and accumulation of these microbes thus contributing to diseases of the oral cavity. ${ }^{11}$ An alternative study though with less evidence says that more of a smooth surface leads to colonisation of pathological bacteria than a rough surface. ${ }^{12}$

Research done with surfaces grafted with dextran along with the bone growth factor BMP-2 and chitosan in conjunction with the cell-adhesive peptide showed reduced bacterial adhesion which promoted osteoblastic activity, thus, enhanced the tissue integration. ${ }^{13,14}$

From the above reports it was clear that the surface modification of a dental implant is considered to have the potential to alleviate pathogenic biofouling 15 and thus, the newer advancement was made to reduce these drawbacks which included coating up of the biomaterials with antimicrobial agents which proved to be more successful, simpler and easier way of modifying the titanium implant. Evidences supporting the use of various antimicrobial agents like phase-transited lysozyme which are coated by the layerby-layer (LBL) self-assembly method creating a multilayered anti-microbial coating ${ }^{16}$, covalent coatings of LC0024 which reduced the $S$. aureus migration but didn't affect the human cell over the titanium surface ${ }^{17}$, tetracycline (TCH)-incorporated nanofibers which was also found to be osteogenic along with bacterial resistance properties ${ }^{18}$, minocycline ${ }^{19}$, TiN, ZrN and (Ti1-xZrx) N reduced the $S$. mutans in particular, ${ }^{20}$ while the silver nano particles, ${ }^{21}, 22$ DMMEP, ${ }^{23}$ Zn-PIII, ${ }^{24}$ cefalotin, ${ }^{25}$ cefotaxime sodium, ${ }^{26}$ tetracycline fibers coating, ${ }^{27}$ have proven to be more effective than just being the surface modification to reduce the bacterial load but also there was an increased ossification of the bone thus, improving the bone to implant contact.

It's very much clear from the evidence that there was no constancy in the results obtained. Each of these studies had taken up different factors, and included various criteria according to their convenience, knowledge and interests. While some studies had coated the implant surface with antibiotics and silver metals to see its resistance towards microorganism other reports suggested the use of nanosurface modification that can reduce the growth of microbes. The merits and demerits are all to be learnt only after an appropriate clinical trial with proper protocol, since most of the evidence include in-vitro and in-vivo results. The desired surface modification needed to improve the implant standards has a long-term debate, as to which is the most effective method in bringing out the required treatment outcomes.

\section{DISCUSSION}

This review gathered evidence from the published article about implants surface texture and its resistance towards bacterial colonisation. Each study had a different pattern of results, based on the implant topography which has a major role play in cell adhesion. ${ }^{28,29}$ Studies showed that rough 
surface area was the reason for the bacterial load ${ }^{11}$ while another study says that it does not lead to succession of the bacterial growth. ${ }^{12}$ Surface roughness is considered to be good for the dental implants to bind with the bony tissue and cause osseointegration. ${ }^{30}$ Most modern implants are made with roughened surface rather than smoother surface as that favours more rapid and higher levels of osseointegration.

A major clinical problem is associated with the biomaterial that is used. Microbes are present at the surgery site and with that begins the race for space. The amount and spread of cells per area decreases with the increasing adhesion of the microflora. ${ }^{31}$ This race for surface is more affected by the type of implant surface as the type of surface texture causes more influence for the bacterial adhesion and increased microbial load. ${ }^{32}$ There are studies to demonstrate that antibiotic-containing fibers (tetracycline) shows a good outcome when coated over the implants ${ }^{27}$ but some report suggests that modification of the surface topography can greatly affect the biofilm adhesion thus, a lesser need for antibiotics coating. 15

Nanoscale surface modifications are being used in either case of promoting or preventing cell adhesion. But yet, there is no such possibility to develop a method that completely eliminates cells attachment onto the surfaces as the entire mechanism of cell attachment is not understood. 33,34

Laser metal sintering has been more efficient in dental implants manufacturing as it is well adapted to the bone. Implant manufactured through this technique shows minimal stress shielding and improved long-term performance ${ }^{35}$ but on the other hand the surface roughness caused by laser sintering increases the bacterial binding over the surface ${ }^{7}$ as previously stated. Surface modification is said to affect the retention of the abutment as well. ${ }^{36}$

Analysis done on the surface texture of implants and biofilm found that silver-implanted surfaces, antibacterial drug-loaded surfaces, antimicrobial peptides surfaces, nanoscale modification and UV-activatable surfaces enhances the microbial resistance activity in comparison to commercial pure titanium. $2,37,38$ Thus, there are various solutions to contrast the establishment of an implant infection. But there lacks a proper clinical trial to get one standard conclusion. ${ }^{39}$

\section{CONCLUSIONS}

The review results had varied patterns of conclusion, there was no constancy in the results obtained. Each study believes in different techniques and different ideologies of the researcher to improve the microbial resistance either by coating or by surface modifying. Due to the varying patterns of the result, it is difficult to identify a definite conclusion for the microbial load over the implant.

\section{Clinical Significance}

Overall, there are many technical solutions to avoid implant failure due to the bacterial load. Many of them exhibit a great potential in preclinical models but the lack of clinical trials hinders the achievement of any proper conclusive data to form a standard protocol for implant manufacturing on the efficacy of structure modification for anti-infective biomaterials. As implants are considered to be the most effective way to replace a missing tooth, standard technique is required for the upcoming generation with better surface texture to have good strength and better microbial resistance.

Financial or other competing interests: None.

Disclosure forms provided by the authors are available with the full text of this article at jemds.com.

\section{REFERENCES}

[1] Palmer RM, Howe LC, Palmer PJ. implants in clinical dentistry. $\quad 2^{\text {nd }} \quad$ edn. CRC Press 2011. https://play.google.com/store/books/details?id=lmnvB QAAQBAJ

[2] Pilliar RM. Overview of surface variability of metallic endosseous dental implants: textured and porous surface-structured designs. Implant Dent 1998;7(4):30514.

[3] Kannan A, Venugopalan S, Ganapathy DM. Effect of coated surfaces influencing screw loosening in implants: a systematic review and meta-analysis. World Journal of Dentistry 2017;8(6):496-502.

[4] Larsson C, Thomsen P, Lausmaa J, et al. Bone response to surface modified titanium implants: studies on electropolished implants with different oxide thicknesses and morphology. Biomaterials 1994;15(13):1062-74.

[5] Subramani K, Jung RE, Molenberg A, et al. Biofilm on dental implants: a review of the literature. Int J Oral Maxillofac Implants 2009;24(4):616-26.

[6] Pacha-Olivenza MA, García-Alonso MC, Tejero R, et al. Microbiologically induced corrosion of titaniumimplants. Orthopaedic Proceedings 2018. https://online.boneandjoint.org.uk/doi/abs/10.1302/1 358-992x.99bsupp_1.eors2016-022

[7] Guan B, Wang H, Xu R, et al. Establishing antibacterial multilayer films on the surface of direct metal laser sintered titanium primed with phase-transited lysozyme. Scientific Reports 2016;6:36408.

[8] Mitik-Dineva N, Wang J, Mocanasu RC, et al. Impact of nano-topography on bacterial attachment. Biotechnol J2008;3(4):536-44.

[9] Mitik-Dineva N, Wang J, Stoddart PR, et al. Nanostructured surfaces control bacterial attachment. International Conference on Nanoscience and Nanotechnology 2008.

[10] Wassmann T, Kreis S, Behr M, et al. The influence of surface texture and wettability on initial bacterial adhesion on titanium and zirconium oxide dental implants. Int J Implant Dent 2017;3(1):32.

[11] Yu P, Wang C, Zhou J, et al. Influence of surface properties on adhesion forces and attachment of streptococcus mutans to zirconia in vitro. Biomed Res Int 2016;2016:8901253

[12] de Freitas MM, da Silva CHP, Groisman M, et al. Comparative analysis of microorganism species succession on three implant surfaces with different roughness: an in vivo study. Implant Dent 2011;20(2):e14-23.

[13] Shi Z, Neoh KG, Kang ET, et al. Bacterial adhesion and osteoblast function on titanium with surface-grafted 
chitosan and immobilized RGD peptide. J Biomed Mater ResA 2008;86(4):865-72.

[14] Shi Z, Neoh KG, Kang ET, et al. Titanium with surfacegrafted dextran and immobilized bone morphogenetic protein-2 for inhibition of bacterial adhesion and enhancement of osteoblast functions. Tissue Eng Part A 2009;15(2):417-26.

[15] Bazaka K, Jacob MV, Crawford RJ, et al. Efficient surface modification of biomaterial to prevent biofilm formation and the attachment of microorganisms. ApplMicrobiolBiotechnol 2012;95(2):299-311.

[16] Zhong X, Song Y, Yang P, et al. Titanium surface priming with phase-transited lysozyme to establish a silver nanoparticle-loaded chitosan/hyaluronic acid antibacterial multilayer via layer-by-layer self-assembly. PLoS One 2016;11(1):e0146957.

[17] Peeters E, Hooyberghs G, Robijns S, et al. An antibiofilm coating of 5-aryl-2-aminoimidazole covalently attached to a titanium surface. J Biomed Mater Res 2019;107(6):1908-19.

[18] Bottino MC, Münchow EA, Albuquerque MTP, et al. Tetracycline-incorporated polymer nanofibers as a potential dental implant surface modifier. J Biomed Mater Res B ApplBiomater 2017;105(7):2085-92.

[19] Lv H, Chen Z, Yang X, et al. Layer-by-layer self-assembly of minocycline-loaded chitosan/alginate multilayer on titanium substrates to inhibit biofilm formation. J Dent 2014;42(11):1464-72.

[20] Ji MK, Park SW, Lee K, et al. Evaluation of antibacterial activity and osteoblast-like cell viability of TiN, $\mathrm{ZrN}$ and (Ti1-xZrx) $\mathrm{N}$ coating on titanium. J AdvProsthodont 2015;7(2):166-71.

[21] Calderon SV, Ferreri I, Henriques M, et al. Nano-galvanic coupling for enhanced $\mathrm{Ag}+$ release in $\mathrm{ZrCN}-\mathrm{Ag}$ films: antibacterial application. Surface Coatings Technology 2016;298:1-6.

[22] Park SW, Lee D, Choi YS, et al. Mesoporous TiO2 implants for loading high dosage of antibacterial agent. Applied Surface Sciences 2014;303:140-6.

[23] Waßmann $M$, Winkel $A$, Haak $K$, et al. Influence of quaternization of ammonium on antibacterial activity and cytocompatibility of thin copolymer layers on titanium. J Biomater Sci Polym Ed 2016;27(15):1507-19.

[24] Fang J, Zhao J, Sun Y, et al. Biocompatibility and antibacterial properties of zinc-ion implantation on titanium. J Hard Tissue Biol 2014;23(1):35-44.

[25] Kang MK, Lee SB, Moon SK, et al. The biomimetic apatitecefalotin coatings on modified titanium. Dent Mater J 2012;31(1):98-105.
[26] He S, Zhou P, Wang L, et al. Antibiotic-decorated titanium with enhanced antibacterial activity through adhesive polydopamine for dental/bone implant. J R Soc Interface 2014;11(95):20140169.

[27] Shahi RG, Albuquerque MTP, Münchow EA, et al. Novel bioactive tetracycline-containing electrospun polymer fibers as a potential antibacterial dental implant coating. Odontology 2017;105(3):354-63.

[28] Gupta A, Dhanraj M, Sivagami G. Status of surface treatment in endosseous implant: a literary overview. Indian J Dent Res 2010;21(3):433-8.

[29] Crawford RJ, Webb HK, Truong VK, et al. Surface topographical factors influencing bacterial attachment. Adv Colloid Interface Sci 2012;179-182:142-9.

[30] Cochran DL. A comparison of endosseous dental implant surfaces. J Periodontol 1999;70(12):1523-39.

[31] Subbiahdoss G, Kuijer R, Grijpma DW, et al. Microbial biofilm growth vs. tissue integration: the race for the surface experimentally studied. ActaBiomater 2009;5(5):1399-404.

[32] Gristina A. Biomaterial-centered infection: microbiol adhesion versus tissue integration. 1987. ClinOrthopRelat Res 2004;(427):4-12.

[33] Bazaka K, Crawford RJ, Ivanova EP. Do bacteria differentiate between degrees of nanoscale surface roughness? Biotechnol J 2011;6(9):1103-14.

[34] Mendonça G, Mendonça DBS, Aragão FJL, et al. Advancing dental implant surface technology--from micron- to nanotopography. Biomaterials 2008;29(28):3822-35.

[35] Traini T, Mangano C, Sammons RL, et al. Direct laser metal sintering as a new approach to fabrication of an isoelastic functionally graded material for manufacture of porous titanium dental implants. Dent Mater 2008;24(11):1525-33.

[36] Ajay R, Suma K, Ali SA, et al. Effect of surface modifications on the retention of cement-retained implant crowns under fatigue loads: an in vitro study. J PharmBioallied Sci 2017;9(Suppl 1):S154-60.

[37] Grischke J, Eberhard J, Stiesch M. Antimicrobial dental implant functionalization strategies-a systematic review. Dent Mater J 2016;35(4):545-58.

[38] Chouirfa H, Bouloussa H, Migonney V, et al. Review of titanium surface modification techniques and coatings for antibacterial applications. ActaBiomater 2019;83:3754.

[39] Campoccia D, Montanaro L, Arciola CR. A review of the biomaterials technologies for infection-resistant surfaces. Biomaterials 2013;34(34):8533-54. 